\title{
Value Creation from Public Healthcare IS
}

\author{
An Action Research Study in the Faroe Islands
}

\author{
Bjarne Rerup Schlichter, Per Svejvig, and Povl Erik Rostgaard Andersen \\ Department of Business Administration, Aarhus University, Denmark \\ $\{$ brs, psve, ros $\}$ a asb. dk
}

\begin{abstract}
The obtainment of value from IT is a recurring theme that has diffused into healthcare information systems (HIS). Having completed the implementation of an integrated HIS, the Faroese Health Service (FHS) has started discussions regarding the obtainment of value from its IT investment which is the subject of this paper. Based on an action research project focusing on the improvement of the stroke process, this paper reveals that it is not possible to distinguish between working processes and HIS and that the realization of value in this context has a much broader significance than mere financial value. During the project, specific key performance indicators (KPIs) were identified and a baseline was established for the stroke process. The outcome is a framework for measuring IS public value as: professional, organizational, patient-perceived and employee-perceived quality as well as learning. Selected non-financial measures for each dimension and their development are presented, e.g., a decrease in mortality.
\end{abstract}

Keywords: Healthcare information systems, IS business value, IS public value, action research, value realization, stroke process.

\section{Introduction}

The creation of value through the use of IT has received increasing attention in recent years. The debate concerning the value of IT also has diffused into healthcare $[1,2]$, and is closely related to a more wide-ranging discussion regarding the performance measures of healthcare organizations [3-6] and public organizations in general [7, 8]. The general discussion concerning the value of IT and the broader discussion regarding the performance measures of healthcare organizations motivated us to start an action research project in the Faroe Islands. The Faroese Health Service (FHS) completed the implementation of an integrated healthcare information system (HIS) in 2010; it was then time to consider reaping the value of the system.

We initiated an action research project with the objective of creating (more) value from the newly implemented HIS. It soon came to our attention that one of the major challenges in this project was to establish a shared and sound understanding of what actually constitutes value in the healthcare setting and how to measure any status or 
progress that is rooted in the ongoing development of the processes. Also, we observed that FHS had defined no targets for value in the initial implementation of the HIS project (i.e., no business case was available).

This paper addresses the need for a more fine-grained framework for measuring (or evaluating) the creation of value in HIS settings. This is a response to Breese [9], who stated in a recent paper that there is a need for the development of theories regarding the creation of value "which are based on in-depth analysis of practice, and acknowledge and incorporate ambiguity and uncertainty." Several studies have explored value creation methods [e.g. 10,11] characterized by the functionalist, rational model that so often dominates the project management community [12], and that, to some extent, lacks the complexity experienced in practice [9]. The paper provides a framework for measuring the IS public value realized in a healthcare setting and demonstrates how the framework was used in practice; thus, it shows the actual value created by a present framework of multidimensional value categories and identifies the key differences between governmental and for-profit organizations. Hence, it shows that different approaches to the measurement of value are needed.

The paper proceeds as follows. The next section reviews the literature regarding value in a public sector context. This is followed by a section describing the action research method applied and the concrete activities in the two action research cycles. We then present the actual creation of value in the project with the offset in an empirically derived structure of value and quality dimensions. We conclude with the implications for research and practice.

\section{From IS Business Value to IS Public Value}

The economic consequences of IS investments have been a recurring theme for many years (at least from the 1980's to the present) [13-15]. The terminology and notions vary when 'value,' 'benefit,' 'outcome' or 'worth' [16] are the terms used and linked to benefit realization management [9-11], value management [17] and beyond. Different semantic understandings are put forward [16]; some focus on financial and productivity measures [18], while others pay attention to both financial and nonfinancial measures, intangibles such as organizational capabilities [13] or strategic impact [19].

A fairly general understanding of value could be described as follows [20, p 140]:

[Value is] the relationship between the satisfaction of need and the resources used in achieving that satisfaction... Value is not absolute, but relative, and may be viewed differently by different parties in differing situations.

Value might be positive or negative for specific stakeholders depending upon the benefits or disadvantages that accrue to them. A more specific definition of IS business value is presented by Schryen [16, p 141]: 
IS business value is the impact of investments in particular IS assets on the multidimensional performance and capabilities of economic entities at various levels, complemented by the ultimate meaning of performance in the economic environment.

The definition of IS business value presented above has multiple facets that have been elaborated further by several scholars in various settings [e.g. 21, 22]. We adapt the following classification in this paper [adapted from 6, 21]:

Table 1. Multidimensional value categories

\begin{tabular}{ll}
\hline Value category & Description \\
\hline Strategic value & To change the nature of how a company competes \\
Informational value & To provide information for decision making in the \\
& company \\
Transactional value & To enable cost savings and support operational man- \\
& agement \\
Transformational value & To change the organizational structure of a company \\
& as a result of the implemented IT systems that pro- \\
& vide a greater capacity for further future benefit \\
& realization. This is typically a longer term effect (lag \\
& effect) \\
Unplanned/emergent value & A result of a transformation or change of process \\
\hline
\end{tabular}

These value categories underline the multidimensional nature of IS business value as suggested by Schryen [16]. Seddon et al. [22] elaborate on differentiating between short-term and long-term values. Short-term values are seen as being connected to the project level and tied to the immediate realization of an IT system while long-term values are connected to the organizational level.

Despite the very comprehensive literature that addresses IS business value [e.g. 13, $14,16]$, it appears to be incomplete when it comes to public organizations. We therefore suggest an alternative concept for public organizations coined 'IS public value' instead of continuing to stretch or force the IS business value concept into the public domain [23].

IS public value research identifies key differences between governmental and forprofit organizations, which naturally leads to other means of evaluating the value of information systems in this sector. The differences are summarized in Table 2 below $[24,25]$ :

Table 2 shows that the public sector needs alternative measures, especially with regard to non-financial measures. However, the public sector might also subscribe to traditional financial measures such as cost savings from the optimization of processes [7]. The IS public value concept has formed the theoretical foundation for this study. 
Table 2. Key differences between governmental and for-profit organizations

\begin{tabular}{|c|c|c|}
\hline & For-profit sector & $\begin{array}{l}\text { Public sector (i.e., health- } \\
\text { care) }\end{array}$ \\
\hline Normative goal & $\begin{array}{l}\text { To maximize shareholders' } \\
\text { wealth }\end{array}$ & Achieve social mission \\
\hline $\begin{array}{l}\text { Principal source } \\
\text { of revenue }\end{array}$ & Sales of services and products & Tax appropriations \\
\hline $\begin{array}{l}\text { Measure of per- } \\
\text { formance }\end{array}$ & Financial bottom line & $\begin{array}{l}\text { Efficiency and effectiveness } \\
\text { in achieving the mission }\end{array}$ \\
\hline $\begin{array}{l}\text { Key calculation } \\
\text { of improvements }\end{array}$ & $\begin{array}{l}\text { Find and exploit distinctive } \\
\text { competence of firm by posi- } \\
\text { tioning it in product/service } \\
\text { markets. }\end{array}$ & $\begin{array}{l}\text { Find better ways to achieve } \\
\text { mission }\end{array}$ \\
\hline
\end{tabular}

\section{$3 \quad$ Methodology}

We initiated an action research study in the Faroe Islands to fulfill the objective of creating value in the FHS's implementation of a HIS. The action research began in 2010 and is expected to come to an end spring 2014. Below, we introduce action research in our context, provide an overview of the research setting and present a detailed description of the actual research process.

\subsection{Action Research}

Action research involves close cooperation between practitioners and researchers to bring about change. It essentially consists of the analysis of a social situation followed by the introduction of changes and the evaluation of the effects [26]. The action research process can be defined as a number of learning cycles consisting of predefined stages; each starts with a diagnosis, a process that involves the joint (practitioner and researcher) identification of problems and their possible underlying causes. Action planning specifies the anticipated actions that may improve or solve the problems identified and action taking refers to the implementation of those specified actions. Evaluation is the assessment of the intervention and learning is the reflection on the activities and outcomes (adapted from [27]).

Action research has become widely accepted [26] and work has been done to conceptualize the approach to enable understanding of and enhance the different elements of action research practice (problem-solving and research activities) [28]. In two action research cycles, we diagnosed, planned and executed change. The final part of each action research cycle was the evaluation of the problem solving based on both process and outcome. Our action research is theoretically premised on an abductive inference style [28] as the project was initiated by a theoretical discussion regarding the obtainment of value from the implementation of a HIS but challenged and enlightened through observations from the case $[21,22]$. 


\subsection{Research Setting}

The Faroe Islands are a self-governing territory within the Kingdom of Denmark with approximately 48,000 inhabitants. The FHS is a relatively small organization consisting of three hospitals and 27 general practices (GPs). In 2005, the FHS began the implementation of an integrated HIS covering hospitals and GPs. The project faced many problems during its first years, even to the point that discussions were held considering the termination of the project, particularly due to the high costs that had been incurred (financial as well as personal) and doubts regarding the value realization [29]. However, the project continued and 530 healthcare professionals are currently using the HIS, which covers all areas of the hospitals and GPs.

Based on the initial implementation process, an evaluation report was prepared that drew on DeLone and McLean's success model [30]. The users were satisfied with the solution, which greatly supported their clinical work, but no initiatives aimed at harvesting the potential value had been planned or implemented [31]. Thus, it was concluded that more needed to be done to obtain proper value and payoff.

\subsection{Research Process}

The action research project was initiated in the fall of 2010 and is expected to come to an end spring 2014. The present part of the project, which focused on how to structure and realize value in a (public) healthcare setting, was prompted by management's wishes to realize value from the previously implemented HIS-system. The researchers have had a high degree of interaction with FHS [32] and have used a variety of research methods related to diagnosing, action planning, action taking, and evaluation and learning. As a result of meetings with staff and observations of the processes in action, it was determined that the first obstacle was to actually define what 'value' means in the present setting and how to actually achieve it based on the limited transformational capacity in FHS. It was then decided that the Good Stroke Process would be replicated to explore and demonstrate the potential for value realization at the medical ward.

During the first action research cycle, it became increasingly difficult to distinguish between the information system (HIS) and the associated working processes; they are like Siamese twins [33] with regard to value creation. Also, it came to our attention that the creation of value in healthcare has a much broader scope than mere financial value [13] and can be divided into three main areas: (1) professional quality (e.g., mortality rate after six months), (2) organizational quality (e.g., length of stay in hospital), and (3) patient-perceived quality (e.g., level of information about the course of disease).

The first workshops helped an understanding to emerge among the healthcare professionals of the need to document the present stroke process in detail. During the very detailed discussions of the process, several KPIs were identified to establish a baseline for the measurement of future improvements and a search for the KPIs was performed. 
In the second action research cycle, we observed that the new HIS made it much easier to collect and calculate KPIs, thus making the measurement of improvements possible. Many KPI candidates emerged during the analysis. While the first cycle of the project identified three value dimensions: professional quality (the clinical treatment of diseases and cure - effectiveness), organizational quality (the optimal use of resources - efficiency), and patient perceptions of quality (customer/patient satisfaction), the second cycle of the project revealed that there was a lack of consideration of the "voice" of the employees. Based on the analysis described above, a baseline of observations and measurements was prepared by FHS staff under the supervision of the researchers, changes in processes were realized and, during the final part of action research cycle two, the measurement and collection of other data was repeated and evaluated against the baseline.

Table 3. Summary Table of Research Cycles

\begin{tabular}{lll}
\hline Cycle & Goal & Learning \\
\hline First action research cycle & $\begin{array}{l}\text { Define value } \\
\text { measures }\end{array}$ & $\begin{array}{l}\text { Value in healthcare has broader scope } \\
\text { than mere financial value } \\
\text { Understanding of need to document } \\
\text { processes }\end{array}$ \\
Second action research cycle & Achieve value & $\begin{array}{l}\text { New HIS made it easier to collect KPI } \\
\text { The lack of the voice of the employees } \\
\text { revealed } \\
\text { Framework for IS value in healthcare } \\
\text { setting established }\end{array}$ \\
\hline
\end{tabular}

The results were presented and discussed during a series of workshops held on the Faroe Islands in October 2013 that included the participation of staff from wards, management and members of the HIS-implementation organization.

\section{$4 \quad$ Value Creation from the Good Stroke Process}

During the two action research process cycles, which are mentioned above, we have been challenged in discussing IS public value at FHS. The first action research cycle revealed three value dimensions (benefit areas): (1) professional quality, (2) organizational quality, and (3) patient perceived quality. These quality dimensions are based on the Danish Healthcare Quality Model [34] and can be linked to specific measures.

However an additional dimension to the three abovementioned was found during the second action research. The healthcare professionals (nurses, doctors, therapists and secretaries) showed an understanding of quality/value which is not covered by the three dimensions 'Employee Perceive Quality' was added.

Fairly late in second cycle we decided also to include learning as an important value dimension due to the fact that projects are an arena for learning [35, 36], which is of future value to organizations although typically with a lag effect.

The more or less empirically derived dimensions are mentioned below: 
Table 4. Empirically derived quality/value dimensions

\begin{tabular}{ll}
\hline Empirical derived dimension & Example \\
\hline Professional quality & Mortality rate after 30 days for stroke patients \\
Organizational quality & Length of stay at hospital \\
Patient perceived quality & Level of information about course of disease \\
Employee Perceived Quality & $\begin{array}{l}\text { The satisfaction of the employees, i.e., do they believe } \\
\text { that the process is well taken care of }\end{array}$ \\
Learning & The capability to work in cross-functional teams \\
\hline
\end{tabular}

Table 4 indicates five fairly broad areas which all can be related to IS public value in HIS settings. The following sections will describe these five dimensions in more detail and present selected measures for these dimensions.

\subsection{Professional Quality}

The measures for professional quality are based on indicators from The Regions Clinical Quality Development Program [37]. These indicators have been defined and produced by a group of professional clinicians representing the public hospital owners and the Danish Government. At Danish hospitals these indicators are obligatory. The hospitals at The Faroe Islands were not using the standardized indicators for measuring the quality in different settings and different diseases as they are not obligated to, but to gain more easy compatible data it was decided to use the indicators for stroke patients for measuring the professional quality in the project. Only some of the indicators were relevant in the actual setting. In table 5 a subset of indicators for the treatment of stroke patients is shown. More indicators are in play in the project, but the validation of the values has not been completed yet.

The year of 2011 is defined as a baseline for our measures. The baseline values have been calculated through an audit of the patient records. Most of the values were picked up from the text based electronic patient system. In the beginning of 2012 more features were added to the HIS system, which means that several templates were set up in the HIS so the registrations of specific events - e.g. assessment done by the physiotherapist (indicator 3 in Table 5) - were more user friendly and precise.

We faced different challenges in the work with clinical data from the electronic patient system. One was the data quality. For example proper registration of different events in regards of time; it could be the time registered for the physiotherapist assessment. Is it the time for the registration or is the time for the assessment? Another challenge was access to the data in the system. Did we get the right data from the database? It is an important question due to the fact that the data model for the system is not documented.

In accordance to those two challenges we put a lot of efforts into the data validation. One important initiative in that respect is presenting and discussing the data with the relevant group of clinicians.

Four of the indicators in Table 5 are process indicators, dealing with treatment and care processes. The last one is an outcome indicator, the only one in our measures. It deals with mortality, and measures the proportion of stroke patients who die within 30 
days after admission. This value is interesting as it is below the limit value in 2012 and 2013. We are in the process of trying to get an explanation of that circumstance.

There is a positive trend in the proportion of patients who were admitted to a stroke unit (indicator 1 in Table 5), but still (in 2013) it is below the limit value of 90\%. The reason for the positive trend is that in the beginning of 2012 one specific unit has been set up as a stroke unit

The second indicator in the table, the proportion of patients getting blood dilute pills shows values below the limit value and indicates and improves process for this area.

Table 5. Measures for a subset of indicators of the professional quality

\begin{tabular}{|c|c|c|c|c|}
\hline Indicator & $\begin{array}{c}\text { Type } \\
\text { Standard/ }\end{array}$ & $\begin{array}{l}\text { Base- } \\
\text { line/ } \\
2011\end{array}$ & 2012 & $\begin{array}{l}\text { 2013, until } \\
\text { mid-October }\end{array}$ \\
\hline $\begin{array}{l}\text { 1. Proportion of patients who } \\
\text { are admitted to a stroke unit } \\
\text { no later than the } 2 \text { nd day of } \\
\text { hospitalization }\end{array}$ & $\begin{array}{l}\text { Process } \\
>=90 \%\end{array}$ & $28 \%$ & $61 \%$ & $80 \%$ \\
\hline $\begin{array}{l}\text { 2. Proportion of patients with } \\
\text { acute ischemic stroke with- } \\
\text { out atrial fibrillation where } \\
\text { treatment with antiplatelet } \\
\text { inhibitor is initiated no later } \\
\text { than the 2nd day of hospitali- } \\
\text { zation }\end{array}$ & $\begin{array}{l}\text { Process } \\
>=95 \%\end{array}$ & $58 \%$ & $91 \%$ & $87 \%$ \\
\hline $\begin{array}{l}\text { 3. Proportion of patients who } \\
\text { undergo a CT/MR scan on } \\
\text { the first day of hospitaliza- } \\
\text { tion }\end{array}$ & $\begin{array}{l}\text { Process } \\
>=80 \%\end{array}$ & $79 \%$ & Missing & Missing \\
\hline $\begin{array}{l}\text { 4. Proportion of patients } \\
\text { assessed by a physiotherapist } \\
\text { no later than the } 2 \text { nd day of } \\
\text { hospitalization in order to } \\
\text { clarify of the extent and type } \\
\text { of rehabilitation and time for } \\
\text { initiation of physiotherapy }\end{array}$ & $\begin{array}{l}\text { Process } \\
>=90 \%\end{array}$ & $45 \%$ & Missing & Missing \\
\hline $\begin{array}{l}\text { 5. Proportion of patients who } \\
\text { die within } 30 \text { days of admis- } \\
\text { sion for acute stroke }\end{array}$ & $\begin{array}{l}\text { Outcome } \\
<=15 \%\end{array}$ & $\begin{array}{l}\text { Missi } \\
\text { ng }\end{array}$ & $8 \%$ & $7 \%$ \\
\hline
\end{tabular}

\subsection{Organizational Quality}

We have focused on one main indicator for the organizational quality, which is the length of the hospital stay. We have the data, but still need to do data validation. There is big dispersion in the data because a small number of patients stay a very long 
time at the hospital for different reasons. Therefore it is needed to make a journal audit and make adjustments in order to give a suitable and detailed picture of the length of stay in hospital for stroke patients.

\subsection{Patient Perceived Quality}

To contribute to the baseline and identify areas for improvement, interviews were held with two stroke patients. The interviews showed that the patients were quite happy with their experiences. One patient said: "I have received good information and I am very satisfied with the stay, I have to admit that..." (Patient 1, 60-year-old male, in his fifth month of hospitalization). We have not been able to conduct interviews with patients after the different initiatives for the stroke patients were implemented.

\subsection{Employee Perceived Quality}

Two surveys were conducted in September 2011 and in September 2013. They were based on a questionnaire and completed by the involved health professionals. The number of participants was respectively 24 in 2011 and 25 in $2013^{1}$. The questionnaire can be seen in appendix A. The questions in the questionnaire were related to informational and communicational issues.

At the same time a number of interviews were completed with the heads of the departments involved. The subject was the work processes related to the treatment of stroke patients and the collaboration between the different professional groups. In the interviews conducted in 2013 questions related to the project process were added because it was relevant to discuss learning from the process itself.

The data from 2011 from both investigations constitutes the baseline for the voice of the clinical staff. In figure 1 the answers from to two questionnaires are depicted. There is a positive tendency in the answers from 2011 to 2013. The average for answers on all 16 question is a bit below the neutral value of 4 in 2011, while in 2013 the value is very close to 5 , thus above the neutral value. The difference between the average in 2011 and 2013 on all questions is 1.2 which is a significant difference.

The questions can be divided into groups. The group with the biggest gap between 2011 and 2013 can be labeled 'Well formulated goals and plans for stroke patients' (question B6, B7, B8 and B9). The smallest difference in answers is related to 'Use of data from other profession groups' (question B13). Here we see a high score above 5 in 2011 as well as in 2013. This means that employees are and were satisfied with the data they can get from other profession groups. These data are and were available through the HIS.

1 The survey has not been conducted as a pairwise study. Some of the respondents are identical; every answer is given anonymous. In 2011 nearly $80 \%$ of the population (all clinicians participating in the treatment and care of stroke patients) participated and in $2013100 \%$ of the population participated. 


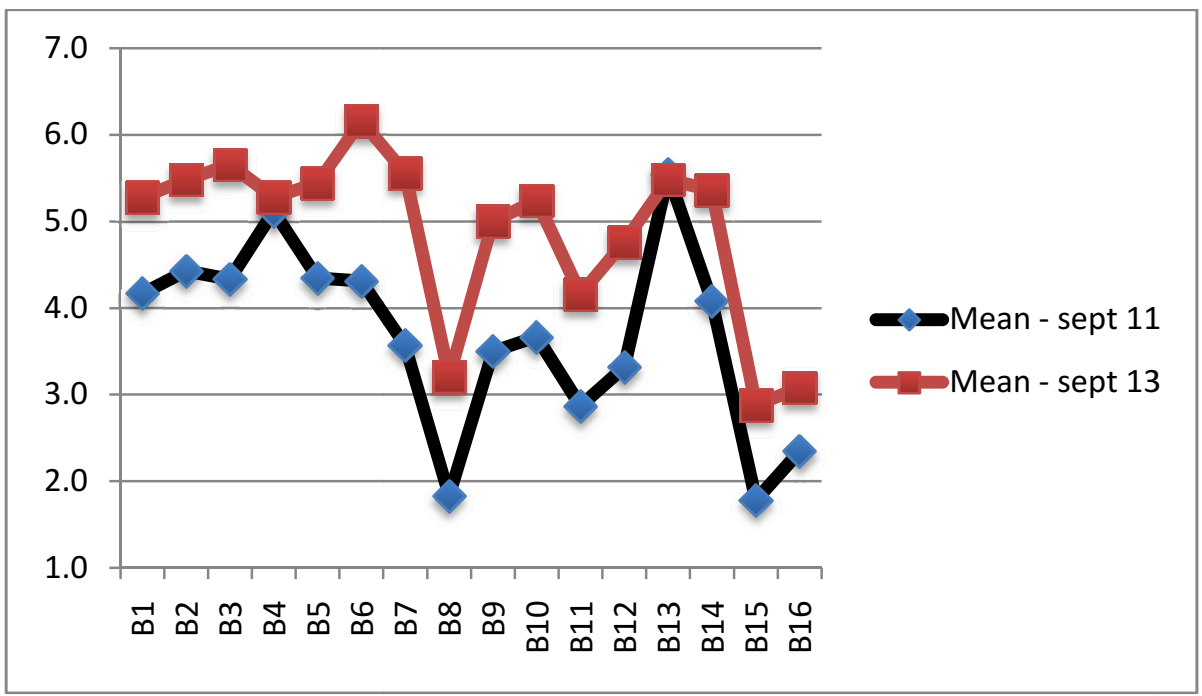

Answers have to be given on a 7-point Likert scale, where $7=$ strongly agree and $1=$ strongly disagree.

Fig. 1. The voice of the clinical staff related to informational and communicational issues in 2011 and 2013. Exact questions are given in annex A.

\subsection{Learning}

The project has created a lot of learning, especially with respect to the process of running a cross-functional project. It was a new way of working for the employees from the different departments. The project manager recognized that the success of the whole initiative (working with this type of interdisciplinary tasks) was caused by the fact that it was set up and completed as a project with a steering committee, a project group and project manager:

"The first things you should clarify is: What you wish to achieve, And if you are approaching it with interdisciplinary and not mono-disciplinarily: Who is in charge?, That there is an action behind it whenever you do something...I think that it has helped that a steering committee, project group and project manager was appointed. Otherwise it would never have worked." and "I feel that the project has been understood. It has been supported which has been great" (Project manager).

Supported by the executive consultant:

"There are some things that you wish to improve because the patient is not feeling well. We are not there yet, but we have come a long way. But if we agree now that we will give this to [the board] and the management group will give this to day-today operations. Then we need some kind of management of this, which we have discussed a bit. We have discussed checklists and regular management meetings, 
where we will address if there are any issues where something is insufficient, is there something we need to be updated on etc. You could say that we took ownership back then (when the project started) and we are holding on to this." (Executive consultant).

But other issues were also present on the learning agenda. The usefulness of clear goals and plans for the treatment of stroke patients is recognized by the clinicians working with stroke patients.

"Well I think the difference is that now it is a bit more established in terms of goals and plans etc. All patients are now being taken care of and we try to set goals for all patients." (Therapist).

The measures set up for the project were also addressed in the interview with the project manager, who was not satisfied with the measures and indicators set up for the professional quality. In her opinion it only covered a limited part of the professional quality. She argues that it is important also to have measures regarding life quality for the stroke patients:

"We have NIP-measurements [the indicators in table 5]. And that is in principle what they are interested in, the board. And every aspect of quality apart from that, we have actually not set any measures for. I believe we should have other measurements as well. It cannot be right that the only measure you have is whether people die or not. That is not quality in my world. You should measure life quality and find out if they get the information needed. You should, in my opinion, move towards this. I know it is hard to measure something like this on patients. They were just super pleased" (Project manager).

Defining value in relation to organizational change never ends. It is important to be open-minded in order to pick up or plan harvesting new benefits in a never ending process when implementing it-projects or other organizational change. The project manager recognizes this and is ready for the challenges related to emergent value.

\section{Discussion and Concluding Remarks}

During the action research project it has been shown how value in a public sector HIS context can be conceptualized and selected actual measurements of baseline values have been provided (2011). Values was measured in 2012 and 2013 after the establishing the baseline showing how value were created by the use of the newly implemented IHIS thus fulfilling one of the objectives of the action research project In this section we will discuss the empirical derived quality/value dimensions using the structure of multidimensional value categories presented earlier in the paper. 
Table 6. IS Value in a Healthcare Setting

\begin{tabular}{|c|c|c|c|c|c|}
\hline Value Category & 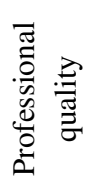 & 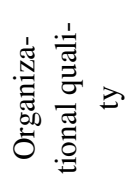 & 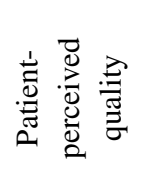 & 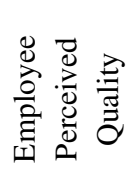 & . \\
\hline Strategic & (1) & + & + & + & + \\
\hline Informational & + & + & (3) & + & + \\
\hline Transactional & + & (2) & + & + & + \\
\hline Transformational & + & + & + & + & (4) \\
\hline Unplanned/emergent & + & + & + & (5) & + \\
\hline
\end{tabular}

Table 6 indicates how IS value can be understood using a two dimensional structure consisting of measured qualities and category of values. For illustrative purposes we have described one example from each cross of rows and columns below following the structure of the Value Categories.

Strategic value (1) can in the context of The Good Stroke Process be related to the main objective of FHS to provide high professional quality treatment of patients. In our case one of the measurements was the 'proportion of patients who are admitted to a stroke unit no later than the 2nd day of hospitalization' which showed improvement by rising from $28 \%$ to $80 \%$ during the project.

Informational value (2) can, naturally, be exemplified by the obvious fact that the structuring on what to measure also created possibility to actually do it and hence provide information for decision making in the FHS. Another example is the Patient Perceived Quality where interviews indicated a fairly high satisfaction which was highly appreciated by the ward management and used to support self-confidence among staff.

Transactional value (3) was shown by addressing organizational quality when measuring the 'length of stay in the hospital' which by the FHS management is seen as an important enabler of cost saving and supporting operational management. Quite interesting this was one, out of many, examples on how difficult it is to agree on concrete definitions due to difficult traditions, procedures and possibilities in the same organizational system of FHS as the project could not provide reliable figures for this indicator.

Transformational value (4) has been achieved by the learning done in the FHS and HIS organization. As such FHS is now in a better position of facilitating new IS value creation projects in the future.

Unplanned/Emergent value (5), which is result of a transformation or change process, was observed when the need to include employee perceived quality came up hence highlighting the importance and potential of including the voice of the employees in the IS value creation process. 
The present research indicates the need and the many challenges to conceptualize both a more fined grained framework for IS public value creation and to assure the actual measurements in a HIS setting. We suggest that the presented framework can be used as a foundation for further research of IS public value in the given context but acknowledges the limitations and need for refinement and challenging of findings in related contexts thus coming closer to the call by Breese [9].

Acknowledgments. The project was done under and with support from Center for IT Project Management and Innovation at Aarhus University and support from the Faroese Ministry of Healthcare. We are thankful for the open doors, friendly interaction and professional discussions provided by the clinical staff (doctors, nurses and therapists at the medical ward) and staff from the HIS unit.

\section{References}

1. Devaraj, S., Kohli, R.: Information technology payoff in the health-care industry: A longitudinal study. Journal of Management Information Systems 16(4), 41-67 (2000)

2. Friedman, C., Wyatt, J.: Evaluation methods in medical informatics, vol. 19. Springer, New York (1997)

3. Murray, C.J.L., Frenk, J.: Ranking 37th - Measuring the Performance of the U.S. Health Care System. New England Journal of Medicine 362(2), 98-99 (2011)

4. Reeves, D., et al.: Analysis: How to identify when a performance indicator has run its course. BMJ 340, c1717 (2011)

5. Bend, J.: Public value and e-health. Institute for Public Policy Research (2004)

6. Sapountzis, S., et al.: Realising benefits in primary healthcare infrastructures. Facilities 27(3), 74-87 (2009)

7. Cole, M., Parston, G.: Unlocking Public Value - A New Model for Achieving High Performance in Public Service Organizations. John Wiley \& Sons, Hoboken (2006)

8. Coats, D., Passmore, E.: Public Value: The Next Steps in Public Service Reform. The Work Foundation (2008)

9. Breese, R.: Benefits realisation management: Panacea or false dawn? International Journal of Project Management 30(3), 341-351 (2012)

10. Bradley, G.: Benefit Realisation Management, 2nd edn. Gower, Farnham (2010)

11. Ward, J., Daniel, E.: Benefits management: How to Increase the Business Value of Your IT Projects. Wiley, West Sussex (2012)

12. Morris, P.W.G., Pinto, J.K., Söderlund, J.: Introduction: Towards the Third Wave of Project Management. In: Morris, P.W.G., Pinto, J.K., Söderlund, J. (eds.) The Oxford Handbook of Project Management, pp. 1-11. Oxford University Press, Oxford (2011)

13. Kohli, R., Grover, V.: Business Value of IT: An Essay on Expanding Research Directions to Keep up with the Times. Journal of the Association for Information Systems 9(1), 23-28, 30-34, 36-39 (2008)

14. Melville, N., Kraemer, K., Gurbaxani, V.: Information Technology and Organizational Performance: An Integrative Model of IT Business Value. MIS Quarterly 28(2), 283-322 (2004)

15. Parker, M., Benson, R., Trainor, H.: Information economics: linking business performance to information technology. Prentice Hall, Englewood Cliffs (1988) 
16. Schryen, G.: Revisiting IS business value research: what we already know, what we still need to know, and how we can get there. Eur. J. Inf. Syst. 22(2), 139-169 (2013)

17. Association for Project Management, APM Body of Knowledge. 6 ed, Buckinghamshire: Association for Project Management (2012)

18. Brynjolfsson, E., Hitt, L.M.: Computing Productivity: Firm-Level Evidence. The Review of Economics and Statistics 85(4), 793-808 (2000)

19. Irani, Z.: Information systems evaluation: navigating through the problem domain. Information \& Management 40(1), 11-24 (2002)

20. European Standard 12973-2000, Value Management (2000)

21. Gregor, S., et al.: The transformational dimension in the realization of business value from information technology. The Journal of Strategic Information Systems 15(3), 249-270 (2006)

22. Seddon, P.B., Calvert, C., Yang, S.: A Multi-Project Model of Key Factors Affecting Organizational Benefits From Enterprise Systems. MIS Quarterly 34(2), 305-A11 (2010)

23. Svejvig, P., Schlichter, B.R., Andersen, P.E.R.: From Business IT Value To Public IT Value - An Action Research Study of Healthcare in the Faroe Islands. In: MCIS 2012, Proceedings. Paper 18. Guimarães, Portugal (2012),

http: / /aisel.aisnet.org/mcis2012/18

24. Moore, M.H.: Managing for Value: Organizational Strategy in For-Profit, Nonprofit, and Governmental Organizations. Nonprofit and Voluntary Sector Quarterly 29(suppl. 1), 183-208 (2000)

25. Moore, M.H.: Creating public value: Strategic management in government. Harvard University Press, Cambridge (1995)

26. Baskerville, R., Myers, M.D.: Special issue on action research in information systems: making is research relevant to practice-foreword. MIS Quarterly 28(3), 329-335 (2004)

27. Myers, M.D.: Qualitative Research in Business \& Management. Sage Publications, London (2009)

28. Mathiassen, L., Chiasson, M., Germonprez, M.: Style Composition in Action Research Publication. MIS Quarterly 36(2), 347-363 (2012)

29. Schlichter, B.R.: Development of trust during large scale system implementation. Journal of Cases on Information Technology 12(2), 1-15 (2010)

30. DeLone, W.H., McLean, E.R.: The DeLone and McLean Model of Information Systems Success: A Ten-year Update. Journal of Management Information Systems 19(4), 9-30 (2003)

31. Andersen, P.E.R., et al.: Effektvurdering af EPJ/THS i det færøske sundhedsvæsen. Aarhus School of Business: Aarhus (2010)

32. Svejvig, P., Andersen, P.E.R.: Setting the stage for benefit realization of healthcare IS: The voice of health professionals. In: OASIS Pre-ICIS Workshop, Shanghai (2011)

33. Alter, S.: The work system method for understanding information systems and information system research. Communications of the Association for Information Systems 9(1), 90-104 (2002)

34. Regions, D: Indicators and Standards in The Danish National Indicator Project (2009), http: / /www.nip.dk/files/Subsites /NIP/Om\%2 0NIP/About\%2 0NIP/DN IP_Acute_Stroke_idicatorform_20100820.pdf (cited March 18, 2012)

35. Hällgren, M., Wilson, T.L.: Mini-muddling: learning from project plan deviations. Journal of Workplace Learning 19(2), 92-107 (2007)

36. Packendorff, J.: Inquiring into the temporary organization: New directions for project management research. Scandinavian Journal of Management 11(4), 319-333 (1995) 
37. Apopleksiregister, D.: Indikatorskema for Dansk Apopleksiregister (October 01, 2013), http: / /www. kcks-vest.dk/files/Subsites/KCKS\%20vest/

De\%20Kliniske\%20Databaser/Apopleksi/

Apopleksi_indikatorskema_fra\%201\%20\%20 september\%

202013_F_26072013.pdf (cited November 20,2013)

\section{Appendix A: Questions from the questionnaire completed by the clinicians in September 2011 and in September 2013.}

Answers were given on a 7 -point Likert scale, where $7=$ strongly agree and $1=$ strongly disagree.

B.1 I find that I have the necessary information about the patient in connection with receiving the patient.

B.2 I find that I have the necessary information about the patient in connection to treatment (during hospitalisation)

B.3 I find that I have the necessary information about the patient in connection to caretaking (during hospitalisation)

B.4 I find that I have the necessary information about the patient in connection with discharging the patient.

B.5 I feel that my knowledge about the disease stroke is good and sufficient enough to treat and nurse patients suffering from this disease.

B.6 I find that there is a well-formulated plan for what acute precautionary measures and examinations should happen to patients with stroke symptoms upon arrival on the ward.

B.7 I find that there is a well-formulated plan for what should happen in terms of treatment and caretaking of the stroke patient in connection to hospitalisation on the ward.

B.8 I find that there is a well-formulated plan for the stroke patient after being discharged from the hospital.

B.9 I feel well-informed about the goals and plans for treatment of stroke patients.

B.10 I find that an individual care- and treatment plan is formulated for every single stroke patient.

B.11 I experience that the entire course of treatment of stroke patients is well managed and coordinated.

B.12 I experience the treatment of stroke patients as being good.

B.13 I find that I have good use of other profession groups' records about stroke patients in my own treatment of patients.

B.14 I experience that I can give patients continuous good information about treatment and caretaking.

B.15 I find that the physical surroundings are good and appropriate in connection to treatment and caretaking of stroke patients.

B.16 I find that the ward is sufficiently staffed to treat and take care of stroke patients. 